\title{
Odour emissions from anaerobic piggery ponds. 1. Results of a three season, 14-month survey
}

\author{
N. Hudson *, E. McGahan, K. Casey, S. Lowe, G. Galvin, P. Jeston, M. Dunlop \\ Department of Primary Industries and Fisheries Queensland, P.O. Box 102, Toowoomba, Queensland 4350, Australia
}

Received 8 February 2006; received in revised form 31 May 2006; accepted 15 June 2006

Available online 7 September 2006

\begin{abstract}
Odour emission rates were measured for seven different anaerobic ponds treating piggery wastes at six to nine discrete locations across the surface of each pond on each sampling occasion over a 14-month period. Emission rate values varied between ponds, between seasons for the same pond and even for the same pond on different days of a sampling week. Average seasonal emission rates ranged from 7.9 to $46.5 \mathrm{OU} / \mathrm{m}^{2} \mathrm{~s}$, while average emission rates ranged from 16.0 to $29.0 \mathrm{OU} / \mathrm{m}^{2}$ s. Factors potentially responsible for the variability in emission rates were investigated, including air and pond liquor temperatures, time of day of sample collection, season and the impact of a prolonged drought.
\end{abstract}

(C) 2007 The State of Queensland, Australia, Dept of Primary Industries and Fisheries. Published by Elsevier Ltd. All rights reserved.

Keywords: Anaerobic; Pig; Swine; Pond; Lagoon

\section{Introduction}

Anaerobic ponds are extensively used for the storage and treatment of piggery wastes in Australia. While they represent simple, low maintenance waste treatment systems, their simplicity limits their capacity to address complex problems such as odour emissions. Pond treatment systems were previously identified as the major source of odour from Australian piggeries (Schulz and Lim, 1993; Dalton et al., 1997; Smith et al., 1999). Following a survey of typical Australian piggeries, Smith et al. (1999) apportioned odour emissions from piggery housing and pond treatment systems $14-30 \%$ and $70-86 \%$, respectively. However, pond treatment systems have undergone very little modification in response to the intensification of the Australian pig industry. As a consequence, the increased volumes of waste generated by efficient and highly intensive modern piggeries are still being treated using traditional

\footnotetext{
* Corresponding author. Tel.: +61 74688 1519; fax: +61 746881192.

E-mail address: neale.hudson@dpi.qld.gov.au (N. Hudson).
}

pond treatment systems. Pond treatment systems, therefore, remain significant odour sources.

The construction of pond treatment systems in Queensland (Casey and McGahan, 2000) have been influenced significantly by the work of Barth (1985a,b). Barth hypothesised that odour emission rate is related to waste loading rate, from which he proposed the Rational Design Standard (RDS). The objectives of the RDS included: (i) minimising the emission of odour from anaerobic treatment ponds; (ii) optimising biological treatment efficiency to minimise odour generation and sludge accumulation; (iii) providing an adequate treatment volume to allow some sludge accumulation to avoid too frequent sludge removal and (iv) encouraging use of the pond liquor for flushing housing or irrigating crops (with dilution, if required) (Casey and McGahan, 2000). Ponds designed in accordance with the RDS, and in particular those designed to realise the second and third objectives above tended to be large. Increasing the size of treatment ponds present a number of challenges to the producers. They are more expensive to construct and are difficult to de-sludge. The large surface areas of these ponds discourage the adoption 
or incorporation of emerging odour control technologies such as permeable pond covers. The existence of a large pond also discourages implementation of technology such as solids separation systems, which might ultimately reduce odour emissions from pond treatment systems. While intuition might suggest that appropriately sized and loaded ponds would produce a lower odour emission rate than an undersized, overloaded pond, there is no scientific evidence to support this hypothesis. It is also a fact that ponds constructed and managed in accordance with the RDS continue to emit odour and on occasions cause offence.

It has long been recognised that odour issues constrain the expansion of intensive livestock industries such as beef cattle feedlots and piggeries. In Australia, it was also recognised that limited data available regarding the magnitude and factors influencing odour emissions from anaerobic ponds constrains the ability of the industry to identify and implement solutions to odour problems. Given the fact that relatively limited data were available regarding the magnitude, impact of seasons, and short-term variability of odour emissions from ponds treating piggery wastes, research was commissioned by the Australian pig industry to fill these knowledge gaps. It was also recognised that significant improvements had been made in the technique of odour sampling and odour assessment using dynamic olfactometry since the original research was published in 1999.

A number of procedures can be followed to estimate waste loading rates (e.g. United States Department of Agriculture, 1992; Midwest Plan Service, 1993; ASAE, 1994; Kruger et al., 1995). Surveys undertaken in Australia identified large differences in total, volatile and fixed solids production rates in measurements of waste streams from the values provided by these texts. As a consequence, McGahan et al. (2000) explored an earlier method for estimation of waste output identified by Barth and Kroes (2004). This method was based on a standardised diet and improved knowledge of the biochemistry and metabolism of the pig. The technique was known as the Digestibility Approximation of Manure Production (DAMP) method. Mc-Gahan et al. (2000) were able to more reliably estimate waste output from a piggery using a modification of the method of Barth and Kroes. It was termed the Dry Matter Digestibility Approximation of Manure Production (DMDAMP) technique.

This paper summarises the data acquired from a 13month, three-season survey of odour emissions from anaerobic ponds at seven different piggeries. Part 2 of this series of articles (Hudson et al., in press) discusses the implications of spatial variability of odour emissions for odour assessment practice.

\section{Methods}

\subsection{Pond selection, sampling locations and sampling schedule}

Odour samples were collected from seven anaerobic piggery ponds, representative of those in common use across Australia, with a known operating history. They were selected primarily to represent a wide range of waste loading rates. Estimated waste loading rates ranged from 51 to $228 \mathrm{~g}$ volatile solids (VS)/ $\mathrm{m}^{3}$ active pond volume/day. Some basic characteristics of the piggeries and the ponds used in this survey are summarised in Tables 1 and 2, respectively. PIGBAL (Casey et al., 1999) was used to estimate the waste load (in terms of mass of volatile solids [VS] per unit of treatment volume per day) to which each pond was subject over the survey period.

Each pond was surveyed using a Trimble Global Positioning System unit, which enabled the pond margins and individual sample points to be located to $\pm 500 \mathrm{~mm}$ accu-

Table 1

Characteristics of piggeries investigated during the project

\begin{tabular}{llllll}
\hline Piggery code & Type of operation & $\begin{array}{l}\text { Size of } \\
\text { operation (SPU) }\end{array}$ & $\begin{array}{l}\text { Waste transport } \\
\text { to pond }\end{array}$ & $\begin{array}{l}\text { Flushing } \\
\text { frequency }\end{array}$ & $\begin{array}{l}\text { Number of treatment } \\
\text { ponds in series }\end{array}$ \\
\hline A & Farrow to finish & 1600 & Gravity & Daily & 2 \\
B & Finisher & 1750 & Pump & Daily & 1 \\
C & Farrow to finish & 10,700 & Pump & Daily & 3 \\
D & Farrow to finish & 7000 & Gravity & Twice-daily & 3 \\
E & Farrow to finish & 12,850 & Gravity & Daily & 3 \\
F & Finisher & 2150 & Gravity & Daily & 2 \\
G & Farrow to finish & Pilot study only & Pump & Daily & 1 \\
\hline
\end{tabular}

Table 2

Characteristics of anaerobic ponds surveyed

\begin{tabular}{lllcccc}
\hline $\begin{array}{l}\text { Piggery } \\
\text { code }\end{array}$ & $\begin{array}{l}\text { Pond dimensions } \\
L \times W(\mathrm{~m})\end{array}$ & $\begin{array}{l}\text { Depth of } \\
\text { pond }(\mathrm{m})\end{array}$ & $\begin{array}{l}\text { Pond } \\
\text { volume }\left(\mathrm{m}^{3}\right)\end{array}$ & $\begin{array}{l}\text { Surface } \\
\text { area }\left(\mathrm{m}^{2}\right)\end{array}$ & $\begin{array}{l}\text { Calculated volatile solids } \\
\text { loading rate }\left(\mathrm{g} \mathrm{VS} / \mathrm{m}^{3} / \mathrm{day}\right)\end{array}$ & $\begin{array}{l}\text { Surface area to } \\
\text { volume ratio }\end{array}$ \\
\hline A & $56 \times 52$ & 3.1 & 6000 & 2946 & 178 & 0.49 \\
B & $64 \times 54$ & 3.2 & 10,800 & 2977 & 50 & 0.27 \\
C & $133 \times 35$ & 4.0 & 8700 & 4600 & 530 & 0.53 \\
D & $110 \times 76$ & 5.5 & 27,000 & 8517 & 166 & 0.32 \\
E & $146 \times 116$ & 7.0 & 73,000 & 16,882 & 84 & 0.23 \\
F & $45 \times 34$ & 4.2 & 4300 & 1154 & 363 & 0.26 \\
G & $41 \times 39$ & 3.4 & 3100 & 1413 & 72.5 & 0.46 \\
\hline
\end{tabular}




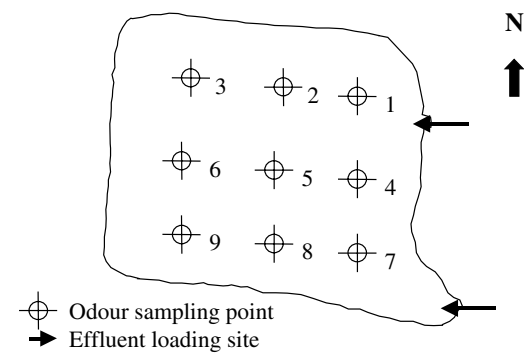

Piggery A

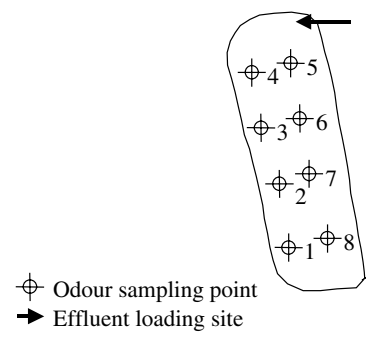

Piggery C

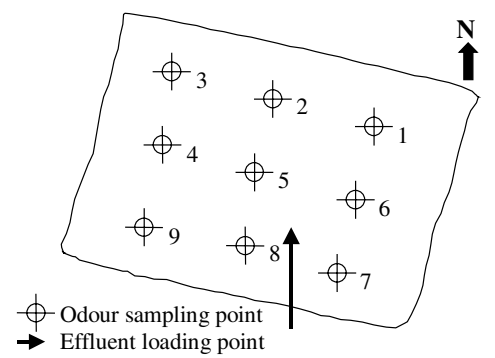

Piggery E

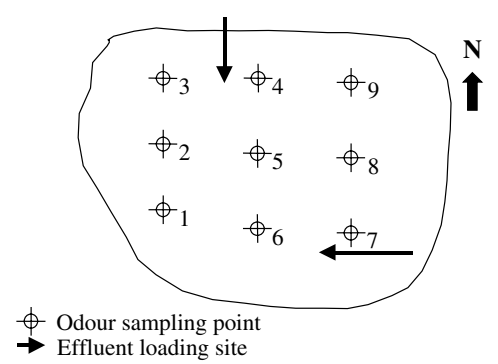

Piggery B

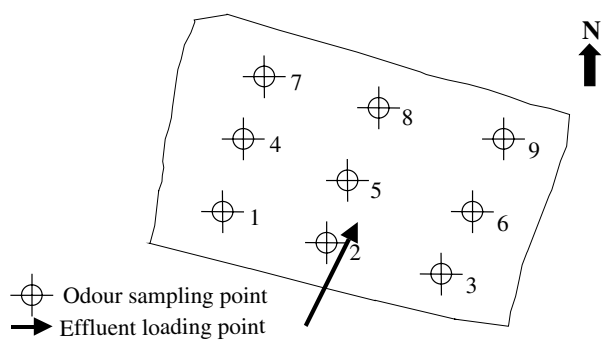

Piggery D

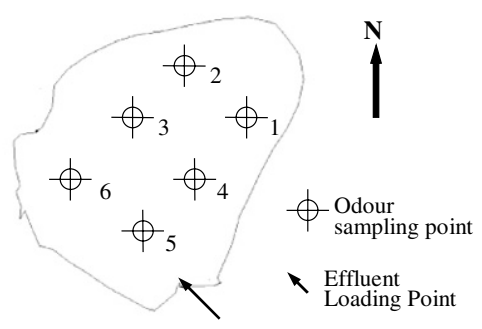

Piggery F

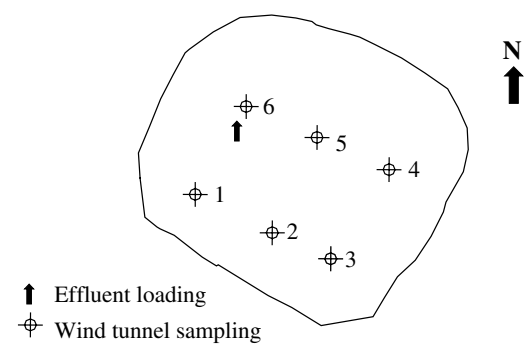

Piggery G

Fig. 1. Schematic of each piggery anaerobic treatment pond and odour sample point locations (not drawn to scale).

racy. The individual odour sample points were located according to a regular array (Fig. 1), which also indicated the position where waste was discharged in the pond. The number of points selected for each pond was related to the pond surface area, so that each point represented an approximately equal area of pond surface. Individual sampling locations were selected so that the point was well away from the internal batter of the pond. This ensured that each sample collected from a specific pond was collected from above a uniform depth of liquor.

Odour samples were collected from the selected ponds during Summer 2000/2001, Winter 2001 and Summer 2001/2002. Samples were collected over a 9-week period during each of the three seasons. Individual ponds were sampled twice in 1 week during this period. A single odour sample was collected from each sampling point of each pond on each sample day. Odour samples were collected twice during each season from the pond at piggery B to assess whether there was significant change in emission rate between the start of the season and the end.

\subsection{Odour sample collection device}

\subsubsection{Wind tunnel device}

Odour samples were collected using a wind tunnel constructed according to the design proposed by the 
University of New South Wales (Jiang et al., 1995; Bliss et al., 1995; Jiang and Kaye, 1996). Modifications were made to the wind tunnel to improve sampling efficiency as described by Wang et al. (2001). This involved the manufacture of a curved $90^{\circ}$ discharge tube that contained a sampling manifold which comprised a hollow, stainless steel cross with an array of holes. These holes were arranged across the tube cross-section to enable equal-area sampling as recommended by Loubet et al. (1999a,b).

Carbon-filtered air was forced into the wind tunnel using a $240 \mathrm{~V}$ fan assembly to generate an internal air velocity of $0.3-0.5 \mathrm{~m} / \mathrm{s}$ in the working section of the tunnel (Jiang et al., 1995). The velocity in the tunnel was determined by measuring the velocity of air discharged from the wind tunnel through a length of $100 \mathrm{~mm}$ diameter PVC pipe $(600 \mathrm{~mm})$. Velocities were measured across the cross-section of the PVC pipe using a Thermo Systems Incorporated (TSI) Model 8355 hot wire anemometer.

\subsubsection{Wind tunnel suspension arrangement}

The gantry previously described in detail by Hudson et al. (2006) was used to suspend the wind tunnel above the pond surface. This gantry consisted of two pontoons constructed from PVC storm water pipe $(300 \mathrm{~mm}$ diameter) and a four-meter wide aluminium frame. A small carriage with nylon rollers allowed lateral movement of the wind tunnel along the frame. Two 12 VDC motors were used to remotely raise and lower the wind tunnel onto the surface of the pond for odour collection. The system enabled the wind tunnel to be moved to any point on the pond surface with minimal disturbance of the liquor.

\subsubsection{Sample collection}

All odour samples were collected using standard DPI procedures (Hudson et al., 2001, 2006). Odour samples were collected in $120 \mathrm{~L} \mathrm{Melinex}{ }^{\mathrm{TM}}$ (polyethylene terephthalate) sample bags. These were placed into a customised rigid sample container and the sample bag was connected directly to the wind tunnel exit stack using $1 / 2^{\prime \prime}$ Teflon ${ }^{\circledR}$ tubing. The air inside the container (outside of the bag) was evacuated at a controlled rate using 12 VDC diaphragm pumps, thereby filling the bags. All components used for sampling were composed of stainless steel or Teflon ${ }^{\circledR}$.

The bags were pre-conditioned by part-filling them with odorous air. This air was then expelled from the sample bag and the sample collection repeated to completely fill the bag. The samples were collected over a period of about $6 \mathrm{~min}$. Samples were stored in the sample collection drum under shade after collection. All samples were analysed within $12 \mathrm{~h}$ of collection.

\subsection{Determination of odour concentrations and emission rates}

\subsubsection{Odour assessment by dynamic olfactometry}

Odour concentrations were determined using the eight panellist, triangular, forced choice dynamic olfactometer developed by the Department of Primary Industries and Fisheries which has been described previously (Nicholas et al., 1999; Zeller et al., 2002). This olfactometer was constructed to comply with the Australian/New Zealand Standard for Dynamic Olfactometry (AS4323.3) (2001), hereafter referred to as "the Standard". The conduct of the odour assessment also occurred in compliance with the Standard.

During a typical odour sample assessment routine, each panellist was first screened with the reference gas ( $n$-butanol) to ensure that his or her detection threshold was within the required concentration range of $20-80 \mathrm{ppb}(\mathrm{v} / \mathrm{v})$. Thereafter, odorous sample was diluted and presented to the panellists in one of three ports, while the other two ports emitted clean, odour-free air. The panellists were required to sniff from the ports and determine whether they could detect a difference between the three ports. Each panellist was allowed a maximum of $15 \mathrm{~s}$ for this assessment. The panellists indicated via a keypad whether they were certain, uncertain or guessing that one of the ports was odorous, as well as from which port the odour (if detectable) was emitted.

This process was repeated, doubling the concentration of odorous air of the previous presentation each time, until each panellist had entered a "certain and correct" response for two consecutive presentations. Each panellist's individual threshold estimate $\left(\bar{Z}_{\text {ITE }}\right)$ was then determined by calculating the geometric mean of the dilution at which the panellist did not respond with certainty and correctly and the first of the two dilutions where the panellist did respond with certainty and correctly. A complete dilution series is defined as a round. Three rounds were completed for each sample provided sufficient sample was available.

At the end of the three rounds, the results of the first round were discarded in accordance with the Standard. The results from rounds two and three were then geometrically averaged $\left(\bar{Z}_{\mathrm{ITE}}\right)$. The ratio between $Z_{\mathrm{ITE}}$ and $\bar{Z}_{\mathrm{ITE}}$ is defined as $\Delta Z$. The calculation of $\Delta Z$ is presented in the following equations:

$$
\begin{aligned}
& \text { If } Z_{\mathrm{ITE}} \geqslant \bar{Z}_{\mathrm{ITE}}, \quad \text { then } \Delta Z=\frac{Z_{\mathrm{ITE}}}{\bar{Z}_{\mathrm{ITE}}} \\
& \text { If } Z_{\mathrm{ITE}} \leqslant \bar{Z}_{\mathrm{ITE}}, \quad \text { then } \Delta Z=\frac{\bar{Z}_{\mathrm{ITE}}}{Z_{\mathrm{ITE}}}
\end{aligned}
$$

If $\Delta Z$ is greater than \pm 5 then all $\bar{Z}_{\text {ITE }}$ values of the panel member with the largest $\Delta Z$ were excluded from the data set. The screening procedure was then repeated, after re-calculation of $\bar{Z}_{\text {ITE }}$ for that measurement. If a panel member again did not comply, the results for this panel member (with the largest $\Delta Z$ ) were omitted. This was repeated until all panel members in the dataset had an acceptable $\Delta Z$ value. The last value of $\bar{Z}_{\text {ITE }}$ was then defined as the odour concentration and expressed as odour units per cubic metre $\left(\mathrm{OU} / \mathrm{m}^{3}\right)$.

\subsubsection{Calculation of odour emission rates}

The odour emission rate, commonly defined as OER or $E$ was calculated using Eq. (3) and expressed in $\mathrm{OU} / \mathrm{m}^{2} \mathrm{~s}$ : 
$E=C V_{\mathrm{t}} \frac{A_{\mathrm{t}}}{A_{\mathrm{s}}}$

where $C$ is the odour concentration in the bag $\left(\mathrm{OU} / \mathrm{m}^{3}\right), V_{\mathrm{t}}$ is the wind speed inside the tunnel $(\mathrm{m} / \mathrm{s}), A_{\mathrm{t}}$ is the cross-sectional area of the tunnel $\left(\mathrm{m}^{2}\right)$, and $A_{\mathrm{s}}$ is the surface area covered by the tunnel $\left(\mathrm{m}^{2}\right)$.

Eq. (3) assumes that all background odour is removed from the air introduced into the wind tunnel by the carbon filter, and there is complete mixing between the emissions and the airflow in the tunnel (Smith and Kelly, 1996).

The calculated OER was then scaled to a standard tunnel wind velocity of $1 \mathrm{~m} / \mathrm{s}$ according to the method of Smith and Watts (1994a). Following determination of emission rates of feedlot pads using two, differently-sized wind tunnels, they concluded that the emission rate $E_{V}$ at a particular tunnel wind speed $V_{\mathrm{t}}$ could be related to the emission rate $E_{1}$ at a tunnel wind speed of $1 \mathrm{~m} / \mathrm{s}$ according to the following relationship:

$\frac{E_{V}}{E_{1}}=V_{\mathrm{t}}^{0.63}$

The exponent of 0.63 was derived as a factor for wind tunnels operated on solid surfaces at feedlots. The value of 0.5 derived from work by Pollock (1997) and Jiang et al. (1995) for liquid surfaces was used. This exponent value was adopted for all odour emission rate calculations using Eq. (4).

\subsection{Statistical and graphical analyses}

The statistical software package Genstat (Lawes Agricultural Trust, 2005) was used to prepare box-and-whisker plots according to the method of Tukey (1977). In these plots, the box spans the interquartile range of the values in the variate, with a line within the box indicating the median. Whiskers extend beyond the ends of the box as far as the minimum and maximum values. If several variates are input into the software, a box is drawn for each of them using the same scale. The plots allow for quick comparison of sets of data derived from different sources. In general, if the boxes overlap, formal significance testing confirms that the data sets are not significantly different.

\subsection{Liquor sampling and analysis}

Electrical conductivity and $\mathrm{pH}$ measurements were made at a number of points (typically five) across the pond surface. Orion Model 130 conductivity and $\mathrm{pH}$ meters were used following appropriate calibration. Composite grab samples of pond liquor were collected approximately $100 \mathrm{~mm}$ below the liquor surface at each point. The $\mathrm{pH}$ and electrical conductivity were measured during each sample visit. These samples were analysed for a range of water quality variables according to standard methods (APHA, 1998).

\section{Results and discussion}

\subsection{General emission rate assessment}

The results of assessments of odour emission rates are summarised in Table 3, while the data are presented graphically as a box-and-whisker plot in Fig. 2. In this plot, each box represents all the emission rate values obtained for that pond on the date indicated. This plot allows comparison of OER between all ponds using all data without regard for seasonal differences, comparison of OER between all ponds by season and comparison of OER between all ponds on the basis of date of sample collection within season.

Fig. 2 indicated that many of the OER results were skewed, i.e., did not follow a normal distribution. This was caused by a relatively large number of low emission rate (ER) results, with a smaller number of high ER values. The box component of each box and whisker plot overlapped significantly with the boxes of the other piggery ponds. In these circumstances, there was unlikely to be a statistically significant difference in OER between the ponds on the basis of ER over the period of the study. The amount of data was not identical for all piggery ponds, with significant periods of missing data for piggery ponds $\mathrm{C}, \mathrm{E}$ and $\mathrm{F}$. These problems with the data set limit the usefulness of formal statistical significance testing. Such testing is also probably not useful for data collected from different places without controlling obvious factors which may influence emission rates, such as waste loading rate, climatic differences and pond morphology.

With the exception of a single sample date in the first summer period, generally lower OERs were observed in Summer 2000/2001 than in other seasons. In the following Winter and in Summer 2001/2002, ERs appeared higher and more variable. While formal significance testing of ER values across seasons and piggeries was not possible, a trend over time was indicated. For Summer 2000/2001, on only one day was the median OER greater than $15 \mathrm{OU} / \mathrm{m}^{2} \mathrm{~s}$. In Winter 2001, the median OER measured on five sample days were greater than $15 \mathrm{OU} / \mathrm{m}^{2} \mathrm{~s}$, while in Summer 2001/2002, the median OER was greater than $20 \mathrm{OU} / \mathrm{m}^{2} \mathrm{~s}$ for nine sample days. Thus, considerable variations were observed in pond OER from any pond between

Table 3

Average OER from the six ponds investigated during the project

\begin{tabular}{lclll}
\hline Piggery & \multicolumn{4}{l}{ Odour emission rate $\left(\mathrm{OU} / \mathrm{m}^{2} \mathrm{~s}\right)$} \\
\cline { 2 - 5 } & $\begin{array}{l}\text { Summer } \\
2000 / 2001\end{array}$ & Winter 2001 & $\begin{array}{l}\text { Summer } \\
2001 / 2002\end{array}$ & $\begin{array}{l}\text { Average over } \\
\text { three seasons }\end{array}$ \\
\hline A & 9.1 & 18.4 & 14.3 & 13.8 \\
B & 7.9 & 15.1 & 25.0 & 16.0 \\
C & 17.3 & 27.4 & - & 22.3 \\
D & 8.7 & - & 46.5 & 20.7 \\
E & 11.4 & 21.8 & 31.5 & 29.0 \\
F & - & 24.5 & 30.2 & 28.4 \\
B2 $^{\text {a }}$ & 14.8 & 15.5 & 24.0 & 18.1 \\
\hline
\end{tabular}

${ }^{\text {a }}$ Second set of data obtained during each season. 


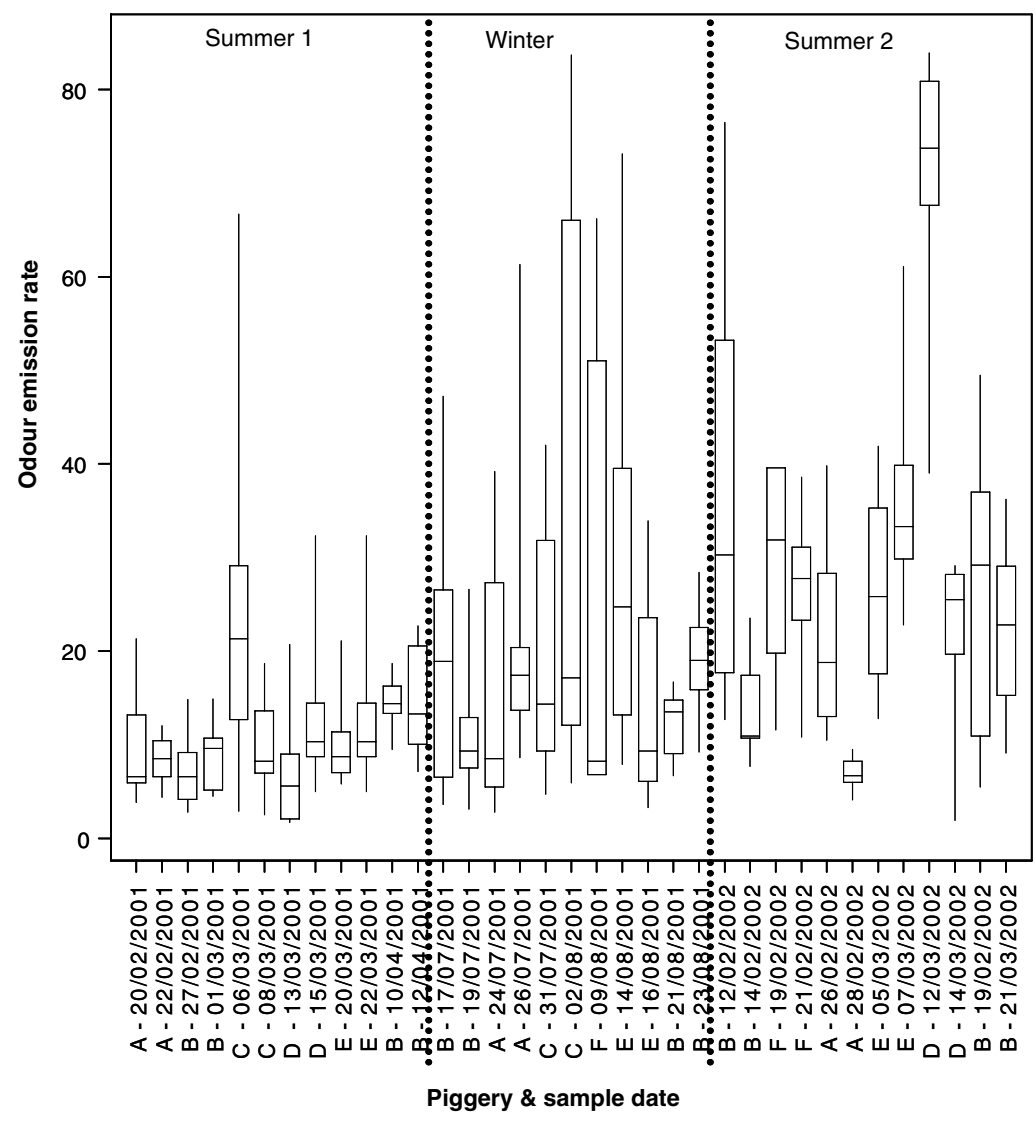

Fig. 2. Odour emission rates $\left(\mathrm{OU} / \mathrm{m}^{2} \mathrm{~s}\right)$ for all piggery ponds by sample day.

sample days within the same week and also in pond OER from any pond in different seasons. An apparent trend of increasing OER over the period of the study was noted, which was confirmed when the individual data points were plotted as a time series graph, as shown in Fig. 3.
A number of factors have been identified which determine the rates of emission of volatile materials from liquid surfaces. These include the speed of air passing over the emitting surface; concentration of volatile material in the air above the liquid surface; concentration of volatile mate-

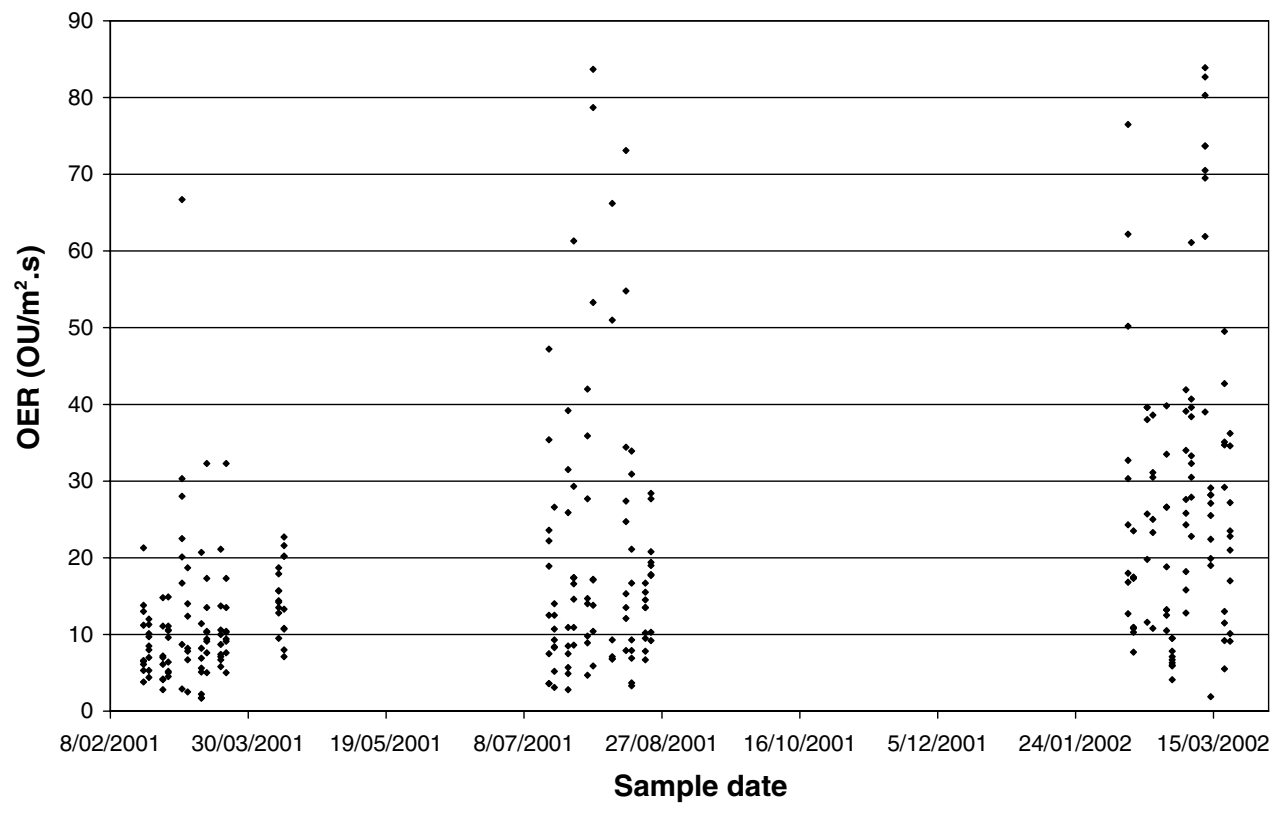

Fig. 3. Discrete odour emission rate values $\left(\mathrm{OU} / \mathrm{m}^{2} \mathrm{~s}\right)$ for all piggery ponds by sample day. 
rial in the liquid phase; temperature of the liquid and temperature of the air above the liquid; general "chemical environment" within the liquid, including $\mathrm{pH}$, ionic strength, solids concentration, etc. (Matson and Harriss, 1995; Thibodeaux, 1996; Tchobanoglous et al., 2003). Standardisation of sampling procedures (through use of a wind tunnel with clearly defined physical dimensions and regulated flushing rate) minimises the influence of some of the factors. The chemical composition of the liquor and physical factors such as the liquor and air temperature therefore assume greater importance. The influence of liquor composition cannot be easily determined from the available water quality data. Single pooled samples representing the liquor of each pond during each season were submitted for analysis.

While no robust relationship was observed between liquor composition and OER, it was worth noting the changes in concentration of selected variables by season. Hydrogen sulphide is a recognised odorant-high concentrations of reduced sulphide in the pond liquor would probably increase odour emission, particularly if the $\mathrm{pH}$ of the pond liquor remained reasonably constant. The ratio of volatile solids to total solids provides an indication of the efficiency of anaerobic decomposition. Increased ratio values indicate that decomposition is less complete and that volatile materials (including odorants) are probably accumulating in the liquor.

Values of these variables are summarised in Table 4. In four sets of available results, sulphide concentrations increased during winter relative to summer 1 . In three of four cases where data were available, sulphide concentrations increased in summer 2 relative to summer 1. For volatile solids: total solids ratios, in two of four sets, the ratio increased during winter relative to summer 1 . In four of

Table 4

Seasonal average concentrations of selected water quality variables

\begin{tabular}{|c|c|c|c|c|c|c|c|}
\hline \multirow{2}{*}{ Piggery } & \multirow{2}{*}{$\begin{array}{l}\text { Water quality variable (units) } \\
\mathrm{pH} \text { (units) }\end{array}$} & \multicolumn{2}{|c|}{ Summer 2000/2001 } & \multicolumn{2}{|c|}{ Winter 2001} & \multicolumn{2}{|c|}{ Summer $2001 / 2002$} \\
\hline & & & 7.4 & & 8.1 & & 7.7 \\
\hline & Total sulphide $(\mathrm{mg} / \mathrm{L})$ & & 0.8 & & 14.8 & & 3.2 \\
\hline & Ammonia-N (mg/L) & & 471 & & 506 & & 540 \\
\hline & Volatile solids (mg/L) & & 967 & & 1164 & & 1420 \\
\hline & Total solids $(\mathrm{mg} / \mathrm{L})$ & & 3120 & & 3377 & & 3190 \\
\hline & Ratio VS/TS $\%$ & & 31 & & 34.5 & & 44.5 \\
\hline \multirow[t]{6}{*}{$\mathrm{B}^{\mathrm{a}}$} & $\mathrm{pH}$ (units) & 7.7 & 7.5 & 8.2 & 8.2 & 7.5 & 7.7 \\
\hline & Total sulphide $(\mathrm{mg} / \mathrm{L})$ & 0.12 & 0.5 & 5.5 & 12.6 & 0.05 & 5.9 \\
\hline & Ammonia-N (mg/L) & 493 & 481 & 515 & 645 & 410 & 420 \\
\hline & Volatile solids (mg/L) & 945 & 938 & $\mathrm{~N} / \mathrm{S}$ & 1067 & 864 & 875 \\
\hline & Total solids $(\mathrm{mg} / \mathrm{L})$ & 3046 & 2753 & $\mathrm{~N} / \mathrm{S}$ & 2894 & 2250 & 1977 \\
\hline & Ratio VS/TS $\%$ & 31 & 34 & $\mathrm{~N} / \mathrm{S}$ & 37 & 38 & 44 \\
\hline \multirow[t]{6}{*}{$\mathrm{C}$} & $\mathrm{pH}$ (units) & & 7.8 & & 7.9 & & $\mathrm{~N} / \mathrm{S}$ \\
\hline & Total sulphide (mg/L) & & 0.51 & & 24 & & $\mathrm{~N} / \mathrm{S}$ \\
\hline & Ammonia-N (mg/L) & & 436 & & 854 & & $\mathrm{~N} / \mathrm{S}$ \\
\hline & Volatile solids $(\mathrm{mg} / \mathrm{L})$ & & 1275 & & 1276 & & $\mathrm{~N} / \mathrm{S}$ \\
\hline & Total solids $(\mathrm{mg} / \mathrm{L})$ & & 3480 & & 3477 & & $\mathrm{~N} / \mathrm{S}$ \\
\hline & Ratio VS/TS $\%$ & & 37 & & 37 & & $\mathrm{~N} / \mathrm{S}$ \\
\hline \multirow[t]{6}{*}{$\mathrm{D}$} & $\mathrm{pH}$ (units) & & 7.7 & & $\mathrm{~N} / \mathrm{S}$ & & 7.6 \\
\hline & Total sulphide (mg/L) & & 1.23 & & $\mathrm{~N} / \mathrm{S}$ & & 0.61 \\
\hline & Ammonia-N (mg/L) & & 319 & & $\mathrm{~N} / \mathrm{S}$ & & 750 \\
\hline & Volatile solids $(\mathrm{mg} / \mathrm{L})$ & & 1332 & & $\mathrm{~N} / \mathrm{S}$ & & 1577 \\
\hline & Total solids $(\mathrm{mg} / \mathrm{L})$ & & 4584 & & $\mathrm{~N} / \mathrm{S}$ & & 4956 \\
\hline & Ratio VS/TS\% & & 29 & & $\mathrm{~N} / \mathrm{S}$ & & 32 \\
\hline \multirow[t]{6}{*}{$\mathrm{E}$} & $\mathrm{pH}$ (units) & & 8 & & 8 & & 7.9 \\
\hline & Total sulphide (mg/L) & & 0.3 & & 12.4 & & 0.51 \\
\hline & Ammonia-N (mg/L) & & 798 & & 817 & & 810 \\
\hline & Volatile solids (mg/L) & & 1311 & & 1118 & & 1433 \\
\hline & Total solids $(\mathrm{mg} / \mathrm{L})$ & & 3614 & & 3800 & & 3893 \\
\hline & Ratio VS/TS\% & & 36 & & 29.4 & & 37 \\
\hline \multirow[t]{6}{*}{$\mathrm{F}$} & pH (units) & & $\mathrm{N} / \mathrm{S}$ & & 8 & & 7.6 \\
\hline & Total sulphide (mg/L) & & $\mathrm{N} / \mathrm{S}$ & & 5 & & 0.33 \\
\hline & Ammonia-N (mg/L) & & $\mathrm{N} / \mathrm{S}$ & & 408 & & 440 \\
\hline & Volatile solids $(\mathrm{mg} / \mathrm{L})$ & & $\mathrm{N} / \mathrm{S}$ & & 620 & & 752 \\
\hline & Total solids $(\mathrm{mg} / \mathrm{L})$ & & $\mathrm{N} / \mathrm{S}$ & & 1749 & & 1588 \\
\hline & Ratio VS/TS $\%$ & & $\mathrm{~N} / \mathrm{S}$ & & 35.5 & & 47.3 \\
\hline
\end{tabular}

$\mathrm{N} / \mathrm{S}$ indicates not sampled or analysed.

${ }^{\text {a }}$ Sampled twice in each season. 
four cases where data were available, the ratio increased in summer 2 relative to summer 1 . Increases in concentrations of hydrogen sulphide and volatile solids were consistent with the increases in OER and provided a basis for partially explaining the emission rates observed.

\subsection{Assessment of seasonal emission rates}

Fig. 2 indicated that OERs for all ponds were highly variable. In this figure, no attempt was made to differentiate between samples collected from different points of a pond on the sample day. While samples were obviously collected from spatially discrete points across the pond surface, they were also collected at different times on the sample day. It was, therefore, not clear from this figure whether the ERs varied spatially (and might appear as variable over time), or varied over time, or over both space and time.

The statistical significance of seasonal differences in OER for each pond was formally tested using Scheffes test (Pollard, 1977). This test indicated that with the exception of piggery A, statistically significant differences in seasonal ER were linked to results for summer 2. This confirmed the impression of increase in ER between Summer 1 and Summer 2 imparted by Fig. 2. The reasons for this apparent trend were unclear. The study area increasingly experienced severe drought conditions over the research period. Mean and maximum daily temperatures increased from Summer 2000/2001 to Summer 2001/2002. Rainfall was low over the entire measurement period. High temperatures and low rainfall would have increased pond salt concentrations, which potentially could impair anaerobic treatment, causing accumulation of odorants derived from anaerobic metabolism. Low rainfall inputs and high evaporation rates would presumably have reduced pond liquid levels, effectively increasing solids waste loading rates. This has been identified as a possible cause of increased OER
Assessment of odour emission rate differences over shorter time scales.

Twelve sets of data were collected for piggery B over the 13-month assessment period. Results for 12 sample dates were tested for significant differences using ANOVA. The test indicated that 26 of the 66 discrete results obtained were significantly different at the $5 \%$ level. While there was an indication of a general increase in OER, on only one occasion were results obtained within a sample week significantly different (12/02/2002 and 17/02/2002) for this pond.

\subsection{Relationship between air temperature and odour emission rate}

The relationship between air temperature and odour emission rate for all samples from all ponds is shown in Fig. 4. The data were subdivided according to season. The relationship between air temperature and OER was very poor, as shown by the low $R^{2}$ values. When interpreting these data, it was important to remember that the air temperature was measured away from the pond, at a temporary weather station situated adjacent to each pond. The data collected at this station might not have accurately represented the conditions within the wind tunnel, where the actual emission took place during each sample collection. Anecdotal observation also indicated that radiant heating of stainless steel and other metal surfaces was very intense, with the surfaces rapidly becoming too hot to touch. These observations indicated that the metal surface temperature might often have been above about $50{ }^{\circ} \mathrm{C}$. The filtration of the ambient air through the carbon filter could also cause compressional heating of the air stream. These processes very likely increased the temperature of the carbon filtered air above ambient temperatures. This hypothesis would remain speculative until specific data were collected

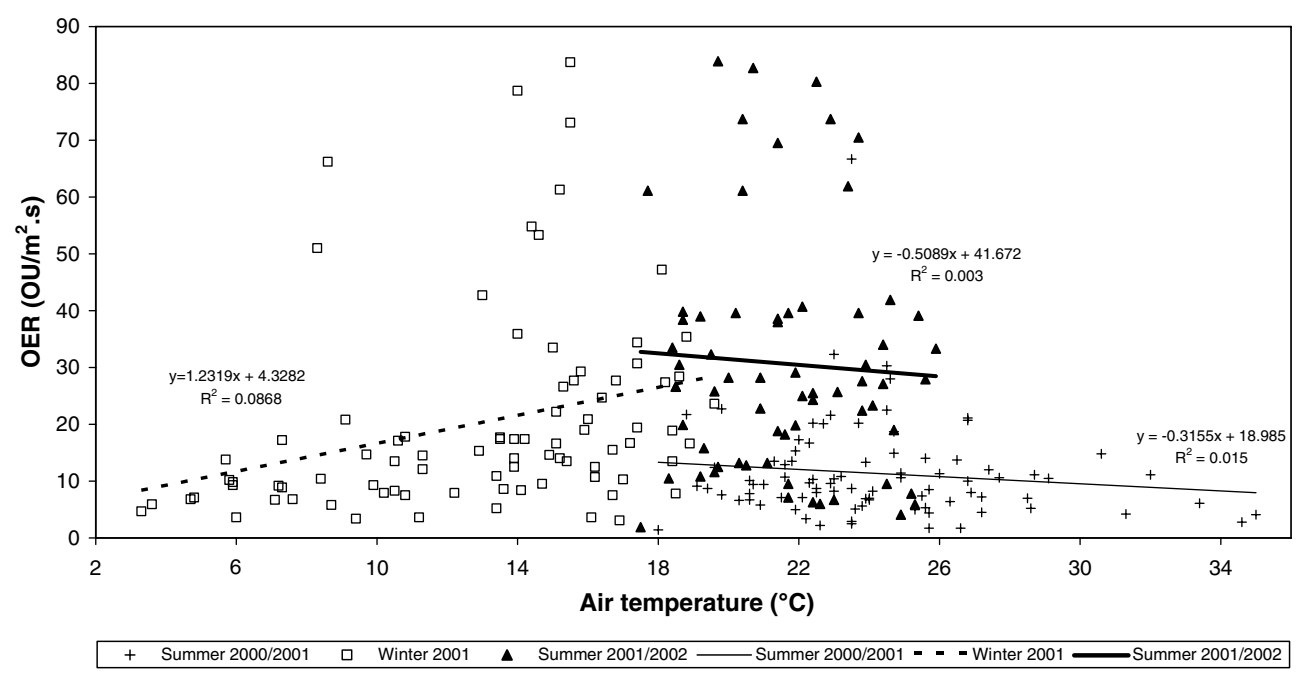

Fig. 4. Seasonal relationship between air temperature and odour emission rate. 
to quantify the potential impact of these heating effects in the sampling system on OER.

\subsection{Relationship between pond liquor temperature and odour emission rate}

Pond liquor surface temperatures were not specifically measured during sample collection at any of the ponds during the sample collection process as a component of this project. However, a semi-continuous record of liquor temperatures was collected at a number of depths at the pond at piggery $\mathrm{B}$ for an unrelated project. It was possible to retrieve temperature data for the near-surface logger from this pond for periods of time that coincided with the collection of three of the sets of odour emission rate data. The relationships between liquor temperature and odour emission rate for these three events are displayed in Fig. 5. While the relationship might appear weak, it was stronger than that between air temperature and odour emission rate, as shown by the $R^{2}$ values in Figs. 4 and 5 .

The relationship between pond liquor temperature and odour emission rate could potentially be improved by optimising the measurement of pond surface temperature during the sampling procedure. The temperature logger was not sited at the point of sample collection, so could have been subject to influences not experienced within the wind tunnel. In addition, the temperature logger was located approximately $300 \mathrm{~mm}$ below the liquor surface. There was probably a significant delay, or lag between surface warming of the pond and transmission of this heat to the underlying liquor. Ideally, the logger should be located at or just below the pond surface within the area covered by the wind tunnel.

The relationship between pond surface temperature and odour emission rate could be further improved by collect- ing odour samples over a longer time period on the day of sampling. This enabled a wider range of surface temperatures to be sampled. On the two days for which corresponding temperature and emission rate data were available, samples were collected between 07:26 and 10:19 $(19 / 07 / 2001)$ and 07:04 and 10:12 (21/08/2001). On these two days, the pond temperature $300 \mathrm{~mm}$ below surface had increased by approximately 0.1 and $0.4{ }^{\circ} \mathrm{C}$, respectively. Collection of odour samples over a wider temperature range should be investigated to ensure that important influences induced by pond temperature have not been missed. Collection of odour samples at other times of the day could allow temperature effects to be assessed over temperature ranges of $1-2{ }^{\circ} \mathrm{C}$.

\subsection{Influence of time of day of sample collection on measured odour emission rate}

As a consequence of practical considerations, almost all of the odour samples were collected in the period between 06:30 and 12:00 of each sample day. This procedure ensured that all odour samples were processed through the olfactometer on the day of sampling. It induced a specific bias in the timing of sample collection, as illustrated in Fig. 6. While pond temperature data for all ponds in seasons were not investigated, this time period was most likely when solar radiation is causing surface warming of the ponds. Future OER investigations should more carefully consider the influence of time of day as a factor influencing emission rate. This ensured that important information was not ignored, or avoidable bias introduced into the emission rate estimation process. For example, it was recognised that odour impacts often occurred late in the afternoon, or early evening when atmospheric dispersion was often reduced. Estimates of emission rate obtained at

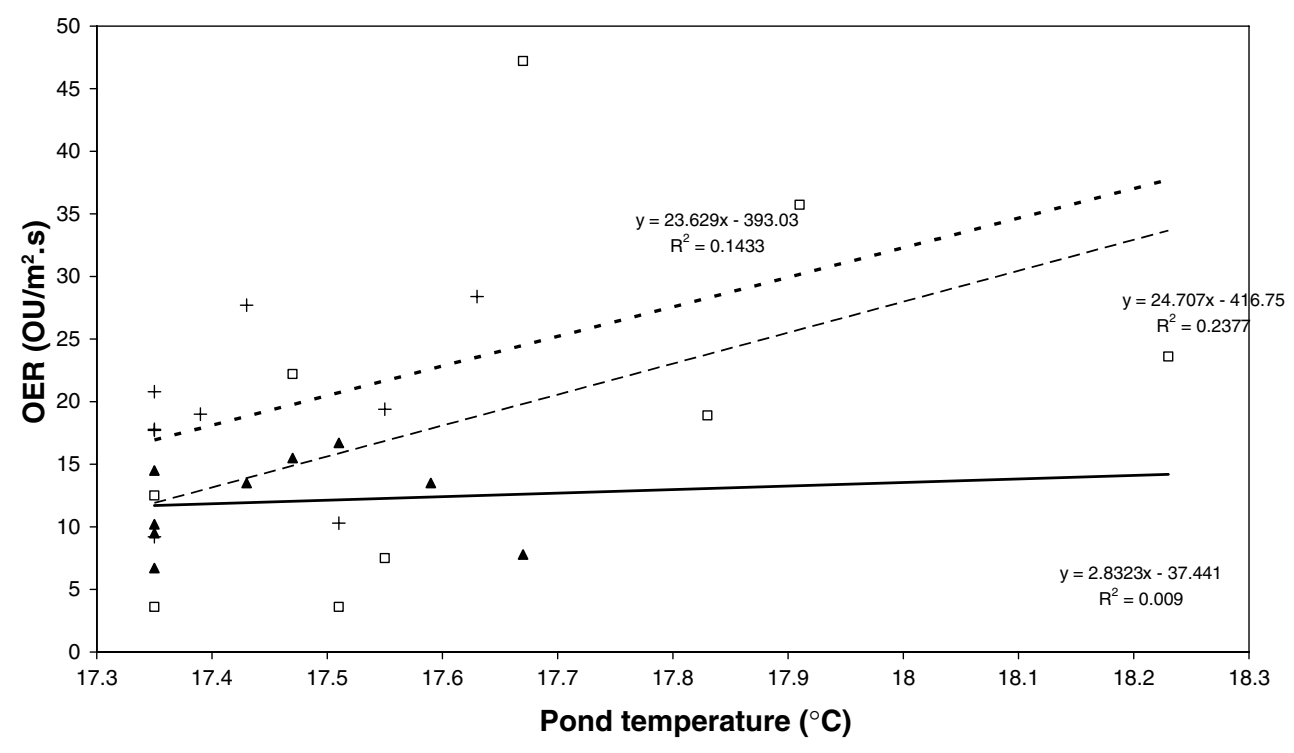

대 $17 / 07 / 2001 \quad 21 / 08 / 2001+23 / 08 / 2001---17 / 08 / 2001-21 / 08 / 2001$ - - 23/08/2001

Fig. 5. Relationship between pond surface temperature and odour emission rate on three discrete sample days. 


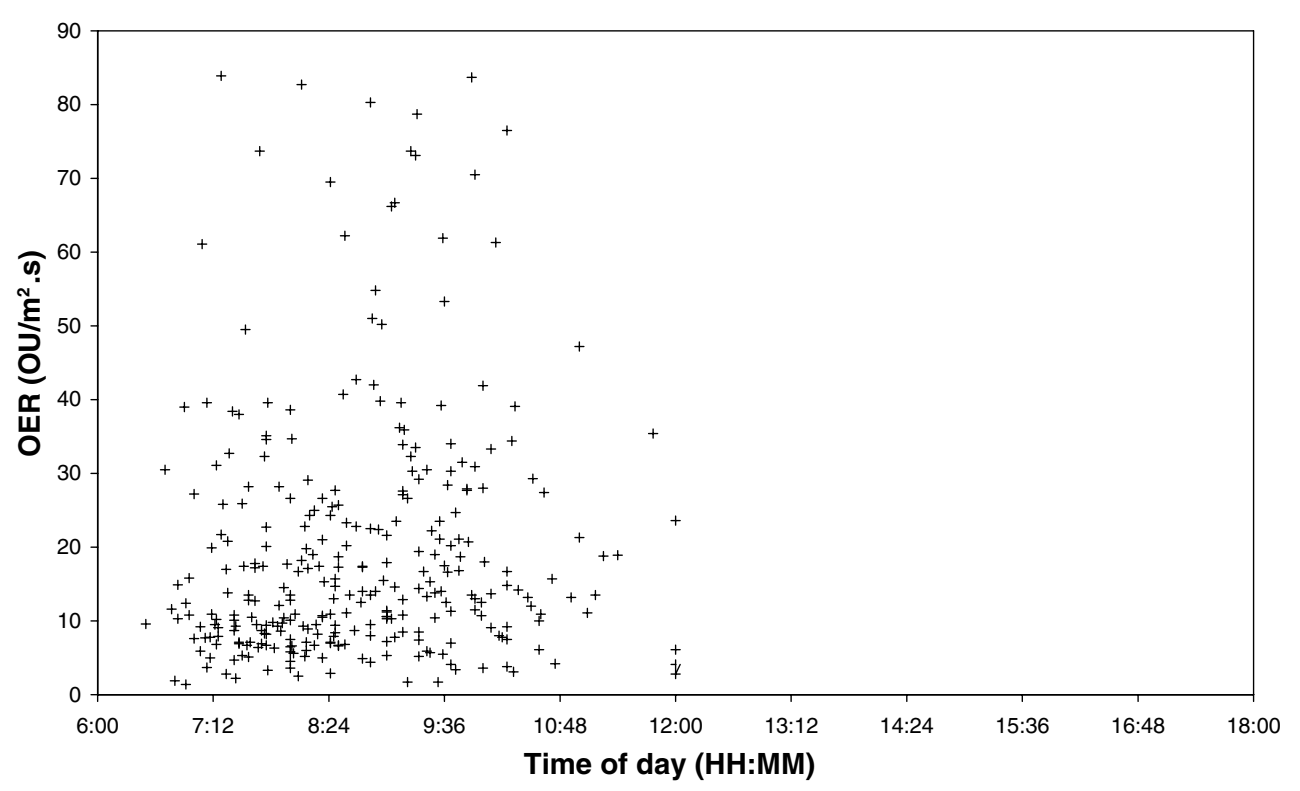

Fig. 6. Relationship between time of sample collection and odour emission rate.

other times of the day might not be appropriate for these critical periods.

\subsection{Comparison with previous survey results}

The measurements previously made by Smith et al. (1999) and Schulz and Lim (1993) also provided a wide range of emission rate values. Smith et al. (1999) made twenty-two discrete odour emission rate measurements at five different ponds. Two sampling techniques were used to calculate these 22 emission rates-a downwind sample, back-calculated approach and a direct approach using a wind tunnel. Single odour samples were used to derive all emission rate estimates. Emission rate values varied from 3.1 to $58.1 \mathrm{OU} / \mathrm{m}^{2} \mathrm{~s}$. On two ponds where multiple samples were collected, emission rates ranged from 3.1 to 31.9 and 14.1 to $58.1 \mathrm{OU} / \mathrm{m}^{2} \mathrm{~s}$. The earlier measurements made by Schulz and Lim (1993) provided emission rate values in a range from 18.9 to $38.0 \mathrm{OU} / \mathrm{m}^{2} \mathrm{~s}$. These were based on an unspecified number of measurements made at four different anaerobic ponds. No consideration was given to factors such as pond loading rates and spatial or temporal variability in either study.

The odour sampling techniques used in both studies differed from those used in this work. Smith et al. (1999) used a wind tunnel previously described for a feedlot odour study (Smith and Watts, 1994b). The device used by Schulz and Lim (1993) was described as a simple enclosed hood placed on the surface of odour generating surfaces with the side which came in contact with the surface left open. While in both previous studies, panellists were screened with $n$-butanol to standardise their response, the odour assessment technique differed procedurally from the standardised methods currently used in Europe and Australasia, making comparison of actual emission rate values difficult. Both previous studies revealed that emission rates measured from a single source might vary quite widely, and would probably be quite different to those measured from a different but similar source. The magnitude of this variability was confirmed in this study. The importance of this variability on dispersion modelling and odour impact assessment remains unknown and requires additional research.

\section{Conclusions}

It could be concluded that currently accepted best practice for odour sampling and impact assessment might require modification. For example, future sampling strategies should recognise the potential for time of day and/or temperature-induced impacts on odour emission rate. It would be relatively simple to detect and account for factors such as these. The present study considerably advances understanding of odour emissions from piggery anaerobic ponds. It is recommended that researchers, regulatory agencies, producers and their consultants consider these data.

\section{Acknowledgement}

This work was funded in part by Australian Pork Limited through Project Number 1628.

\section{References}

APHA, 1998. Standard Methods for the Examination of Water and Wastewater, 20th ed. American Public Health Association, Washington.

ASAE, 1994. Design of Anaerobic Lagoons for Animal Waste Management. ASAE.

Barth, C.L., 1985a. Lagoon planning and design for livestock systems. Agricultural Waste Utilization and Management-Fifth Symposium of Agricultural Wastes. 
Barth, C.L., 1985b. The rational design standard for anaerobic livestock lagoons. Agricultural Waste Utilization and Management-Fifth Symposium of Agricultural Wastes. American Society of Agricultural Engineers, St. Joseph, Michigan.

Bliss, P., Jiang, K., Schulz, T., 1995. The development of a sampling system for determining odor emission rates from areal surfaces. Part II: Mathematical model. Journal of Air and Waste Management Association 45, 989-994.

Casey, K., McGahan, E., 2000. Anaerobic Ponds: Piggery Waste Management. Queensland Department of Primary Industries, Toowoomba, Queensland, Australia.

Casey, K., McGahan, E., Atzeni, M.A., Gardner, E., Frizzo, R., 1999. PIGBAL: A Nutrient Balance Model for Intensive Piggeries. Version 2.12. Queensland Department of Primary Industries, Toowoomba, Queensland, Australia.

Dalton, P.A., Harris, T.R., Smith, R.J., Hancock, N.H., 1997. Odour Emissions from Piggery Buildings. National Workshop on Odour Measurement Standardisation, University of New South Wales, Sydney, University of New South Wales, Sydney.

Hudson, N., Casey, K., Melvin, S., Nicholas, P., 2001. Laboratory-scale investigation of supported permeable covers for the management of odour emissions from anaerobic waste ponds. Water Science and Technology 44 (9), 317-326.

Hudson, N., Bell, K., McGahan, E., Lowe, S., Galvin, G., Casey, K., in press. Odour emissions from anaerobic piggery ponds. 2: Improving estimates of emission rate through recognition of spatial variability. Bioresource Technology, doi:10.1016/j.biortech.2006.06.013.

Hudson, N., Gies, A., Duperouzel, D., 2006. Assessment of permeable covers for odour reduction in piggery effluent ponds. 2. Field-scale trials. Bioresource Technology 97, 2015-2023.

Jiang, K., Kaye, R., 1996. Comparison study on portable wind tunnel system and isolation chamber for determination of VOC's from areal sources. Water Science and Technology 34 (3-4), $583-589$.

Jiang, K., Bliss, P., Schulz, T., 1995. The development of a sampling system for determining odor emission rates from areal surfaces. Part I: Aerodynamic performance. Journal of Air and Waste Management Association 45, 917-922.

Kruger, I., Taylor, G., Ferrier, M., 1995. Effluent at Work, Tamworth, NSW 2340, NSW Agriculture, Australia.

Lawes Agricultural Trust, 2005. GenStat. Version 8.1.0.152. Lawes Agricultural Trust, Rothamsted.

Loubet, B., Cellier, P., Flura, D., Genermont, S., 1999a. An evaluation of the wind tunnel technique for estimating ammonia volatilization from land. Part 1: Analysis and improvement of accuracy. Journal of Agricultural Engineering Research 72, 71-81.

Loubet, B., Cellier, P., Flura, D., Genermont, S., 1999b. An evaluation of the wind tunnel technique for estimating ammonia volatilization from land. Part 2: Influence of the tunnel on transfer process. Journal of Agricultural Engineering Research 72, 83-92.

Matson, P., Harriss, R., 1995. Biogenic Trace Gases: Measuring Emissions from Soil and Water. Blackwell Science Limited, Oxford.

McGahan, E.J., Casey, K.D., Duperouzel, D., Smits, R.J., 2000. Validation of waste estimation theory for intensive pig production systems. In: Eighth International Symposium on Animal, Agricultural and Food Processing Wastes, Des Moines, Iowa, pp. 96-102.

Midwest Plan Service, 1993. Livestock Waste Facilities Handbook, MWPS-18 ed. Iowa State University, Ames, Iowa.

Nicholas, P.J., Casey, K.D., James, V., 1999. In: Kopinski, J., (Ed.), Redevelopment of the DPI ILEMS Forced-Choice Dynamic Olfactometer. Third Queensland Pig Science Seminar, University of Queensland, Gatton, Queensland Department of Primary Industries, Queensland. 39p.

Pollard, J., 1977. A Handbook of Numerical and Statistical Techniques with Examples Mainly from the Life Sciences. Cambridge University Press, Cambridge.

Pollock, T.J., 1997. Dispersion modelling to predict off-site impact of odour sources. In: Jiang, J. (Ed.), Proceedings of the National Workshop on Odour Measurement Standardisation, UNSW, Sydney. UNSW, Sydney, pp. 95-104.

Schulz, T., Lim, B.P.L., 1993. Piggery odours-monitoring and management. Agricultural odours workshop, Clean Air Society of Australia and New Zealand and Australian Water and Wastewater Association, Dubbo, New South Wales. CASANZ.

Smith, R.J., Kelly, J., 1996. A comparison of two methods for estimating odour emissions from area sources. In: International Conference on Air Pollution from Agricultural Operations, Kansas City, Missouri.

Smith, R., Watts, P., 1994a. Determination of odour emission rates from cattle feedlots: Part 1, A review. Journal of Agricultural Engineering Research 57, 145-155.

Smith, R., Watts, P., 1994b. Determination of odour emission rates from cattle feedlots: Part 2, Evaluation of two wind tunnels of different size. Journal of Agricultural Engineering Research 58, 231-240.

Smith, R., Dalton, P., DeBruyn, J., 1999. Assessment and reduction of the odour impact of piggeries. NCEA 1/0989, Pig Research \& Development Corporation: Canberra, ACT.

Standards Australia and Standards New Zealand, 2001. Stationary source emissions. Part 3: Determination of odour concentration by dynamic olfactometry. AS/NZS 4323.3:2001, Standards Australia: Strathfield, New South Wales.

Tchobanoglous, G., Burton, F., Stensel, H., 2003. Wastewater Engineering: Treatment and Reuse. fourth ed. McGraw-Hill, New York.

Thibodeaux, L., 1996. Environmental Chemodynamics: Movement of Chemicals in Air, Water, and Soil. second ed. John Wiley \& Sons, New York.

Tukey, J., 1977. Exploratory Data Analysis. Addison-Wesley, Reading, MA.

United States Department of Agriculture, 1992. Waste CharacteristicsAgricultural Waste Management Field Handbook Part 651. USDA Soil Conservation Service, Washington, DC.

Wang, X., Jiang, J., Kaye, R., 2001. Improvement of wind tunnel sampling system for odour and VOCs. In: 1st IWA International Conference on Odour and VOCs: Measurement, Regulation and Control Techniques, University of New South Wales, Sydney, pp. 147-154.

Zeller, L., Atzeni, M., Jacuinde, G., 2002. Automation of a dynamic olfactometer for odour determination. In: Australian Conference on Engineering in Agriculture, Wagga Wagga, Australia. 